\title{
Correspondence
}

\section{Recognition and reporting of sexual abuse}

Sir,

There will be much concern about the memorandum on child abuse central register systems issued by the Department of Health and Social Security (LASSL (84) 1980). The subject likely to provoke most discussion is that severe emotional abuse should be included among the conditions to be registered. We were disappointed that despite recommendations that sexual abuse of children should be placed under the definition of child abuse and be dealt with under the same procedures, the DHSS did not list it as a separate category. We think that this reluctance to take a strong, clear line on the handling of child sexual abuse will merely make worse the existing confusion among professions, and lead to further lack of activity. Area review committees disagree about whether a child who has experienced attempted or actual sexual intercourse, or other inappropriate genital contact with an adult, should be placed on a child abuse register, ${ }^{1}$ and whether the procedures applicable to physical abuse should be applied also to sexual abuse. Few sexually-abused children have been placed on such a register.

We are concerned that there is no clear policy or procedure for handling cases of sexual abuse in the UK. Practitioners say they are bewildered by the problems of case management, quite apart from uncertainty about how to offer treatment. Our current level of knowledge and understanding of sexual abuse is equal to that pertaining to physical abuse in the late 1960 s. There is much denial and emotional revulsion, and statistics of incidence are difficult to obtain; we suspect that there is gross underdiagnosis. In the USA figures of 1.3 per 1000 children are now being quoted, and our own incidence was at least 1 per 6000 children a year. ${ }^{1}$ In addition, punitive attitudes prevail which deter professionals from recognising cases since police involvement and prosecution for incest or indecent assault are likely, and neither perpetrators nor victims cone forward for help. Disintegration rather than rehabilitation of the family unit is likely because the father is sent to jail or the child victim placed outside the family, often resulting in double victimisation of the child.

It is disappointing that the DHSS decided not to give child sexual abuse a separate category as no mechanism exists for collecting data, apart from criminal statistics which are misleading. It has been argued that it is difficult to define child sexual abuse but we feel it is possible to provide a satisfactory operational definition and typology thanks to the pioneering work of American colleaguessuch as Henry Kempe ${ }^{2}$ and the Giarettos. ${ }^{3}$

We believe that registration and the application of child abuse procedures would be a step towards better management and the establishment of treatment programmes.

\section{References}

1 Bentovim A, Beezley-Mrazek P, Lynch M. Sexually abused children-are they seen by paediatricians and child psychiatrists? (abstract). Arch Dis Child 1980; 55: 731.

2 Kempe R S, Kempe C H. Child abuse. London: Fontana/ Open Books, 1978: 60-76.

3 Giaretto H. Humanistic treatment of father-daughter incest. Child Abuse and Neglect 1977; 1 : 411-26.

ArNon Bentovim The Hospital for Sick Children, Great Ormond Street, London WCIN 3JH

MARGARET LYNCH Guy's Hospital, St Thomas Street, London SEI 9RT

\section{Prostaglandins in salmonella-induced secretory diarrhoea}

Sir,

Prostaglandins produce secretion of fluid and electrolytes in the intestine, via activation of the adenyl cyclasecyclic AMP mechanism. ${ }^{1}$ The adenyl-cyclase-cyclic AMP mechanism also accounts for the secretory diarrhoea which occurs during experimental salmonella gastroenteritis. ${ }^{2}$ On the basis of animal experimental studies using prostaglandin synthetase inhibitors, it has been inferred that prostaglandins might be involved in the activation of adenyl cyclase by salmonella organisms; ${ }^{2}$ however, this hypothesis remains unsubstantiated. ${ }^{3}$

We are currently studying plasma prostaglandin levels in childhood diarrhoeal disorders. A 16-month-old girl, in hospital in our department because of failure to thrive, had a plasma level of 13-14-dehydro-15-keto-PG $F_{2} \alpha$ of $4 \mathrm{pg} / \mathrm{ml}$ (laboratory upper limits in adults $-40 \mathrm{pg} / \mathrm{ml}$ ), while her bowel motions were normal. Two days later, she fortuitously developed a profuse, secretory-type diarrhoea of sudden onset (up to 16 watery bowel motions a day with high electrolyte content); Salmonella sp. group B was subsequently isolated from stool cultures. During this episode, a repeat estimation of the plasma PG $F_{2} \propto$ metabolite showed a level of $45 \mathrm{pg} / \mathrm{ml}$, a more than 10-fold increase compared with the prediarrhoeal state.

Our demonstration of the acute rise in prostaglandin accompanying this diarrhoea, lends clinical support to 
the experimentally based hypothesis that salmonellainduced secretory diarrhoea is mediated by prostaglandins. Oral aspirin has recently been reported to reduce fluid losses in childhood gastroenteritis by mechanisms not specified. ${ }^{4}$ In the light of the findings in our patient this effect may, in part, be attributed to the prostaglandin synthetase-inhibiting property of aspirin.

\section{References}

1 Kimberg D V, Field M, Johnson J, Henderson A, Gershon E. Stimulation of intestinal mucosal adenyl cyclase by cholera enterotoxin and prostaglandins. J Clin Invest 1971 ; 50: 1218-30.

2 Gianella R A, Gots R E, Charney A N, Greenough W B, Formal $\mathrm{S}$ B. Pathogenesis of salmonella-mediated intestinal secretion. Activation of adenylate cyclase and inhibition by indomethacin. Gastroenterology 1975; 69: 1238-45.

3 Gianella R A. Importance of the intestinal inflammatory reaction in salmonella-mediated intestinal secretion. Infect Immun 1979; 23: 140-5.

4 Burke V, Gracey M, Suharyono, Sunoto. Reduction by aspirin of intestinal fluid-loss in acute childhood gastroenteritis. Lancet 1980; i: 1329-30.

S H Korman, U Alon, and M Berant Department of Paediatrics ' $B$ ', Rambam Medical Center, Technion-Faculty of Medicine, Haifa, Israel

S BAUMINGER Unit of Reproductive Endocrinology, Ichilov Hospital, Tel Aviv, Israel

\section{Transpyloric feeding in infants undergoing intensive care}

Sir,

Experience with nasojejunal (NJ) feeding using the Vygon preweighted silicone rubber tube at the Jessop Hospital for Women, Sheffield, has been similar to that described by Dryburgh. ${ }^{1}$ Between January 1977 and December 197960 infants (mean birthweight $1.37 \mathrm{~kg}$, range $0 \cdot 50-2 \cdot 5$ ) were fed by this route for a mean duration of 29.4 days (range 5-69) and have been described in detail elsewhere. ${ }^{2}$ Thirty-nine required ventilatory assistance. The following observations may be of help to clinicians who wish to use $\mathrm{NJ}$ feeding for infants of low birthweights.

In our unit nursing staff were taught to pass $\mathrm{NJ}$ tubes using a similar method to that of Dryburgh except that gastric air insufflation was used to help passage through the pylorus. ${ }^{3}$ Eighty-five per cent of initial tube placements were successful at the first attempt (confirmed radiographically) in infants of birthweights of at least $1 \mathrm{~kg}$. In smaller infants greater difficulty was encountered due to poor peristalis; and in infants weighing $0.70 \mathrm{~kg}$ or less, the stainless steel weight did not readily negotiate the tight curve of the duodenal loop, apparently owing to its length $(1 \mathrm{~cm})$, and this led to a delay in starting enteral feedings. A NJ tube with a shorter weight (say $0.5 \mathrm{~cm}$ ) might pass more quickly. In $70 \%$ of our infants the NJ tube became dislodged between 1 and 7 times either by the infant or the nursing staff despite great care being taken to fix the tube and to restrain the arms of the infant; 'spontaneous' return of the tube tip to the stomach was generally due to dislodgement during suctioning of the pharynx. Two infants $(1.12 \mathrm{~kg}, 27$ weeks' gestation; 0.84 $\mathrm{kg}, 26$ weeks' gestation) who were mask-ventilated for apnoeic attacks had repeated NJ tube dislodgements. Both these infants died and at necropsy there was evidence of pulmonary milk aspiration. The combination of mask ventilation and $\mathrm{NJ}$ feeding was therefore stopped in our nursery. We did not routinely change NJ tubes, and tubes which were left in situ for at least 60 days showed no sign of stiffening, unlike the polyvinylchloride tubes which stiffen within 3 or 4 days. There was no case of bowel perforation or necrotising enterocolitis, but one infant $(0.85 \mathrm{~kg}, 30$ weeks' gestation) had a torrential gastrointestinal haemorrhage after 15 days of $\mathrm{NJ}$ feeding and subsequently developed an oesophageal stricture requiring a prolonged time in hospital.

In infants of 30 weeks' gestation or less, the sodium content of currently available standard infant formulae (for example, Cow and Gate Premium; $1 \mathrm{mmol} / 100 \mathrm{ml}$ ) was inadequate because of renal losses owing to tubular immaturity. ${ }^{4}$ Supplements of sodium (3-5 and sometimes as much as $9 \mathrm{mmol} / \mathrm{kg}$ per 24 hours) were required to prevent hyponatraemia until the infant was about 34 weeks' corrected age.

Continuous NJ feeding did offer an advantage over intermittent nasogastric feeding in the mean time $( \pm$ SD) spent by nursing staff in feeding-related activities (NJ $19.7 \pm 5.8$; nasogastric $95.7 \pm 25$ minutes a baby per 24 hours; $\mathrm{P}<0.001$ ). It was a fairly safe technique using the commercially available preweighted silicone rubber tube, and made small demands on financial resources and nursing time.

\section{References}

1 Dryburgh E. Transpyloric feeding in 49 infants undergoing intensive care. Arch Dis Child 1980; 55: 879-82.

2 Whitfield M F. Some effects of nutrition on growth and metabolism in the newborn infant. MD thesis, University of Edinburgh 1981.

3 Schaffblass E, Kuhns L R, Wyman M L. Gastric air insufflation as an aid to placement of oroduodenal tubes. J Pediatr 1976; 89: 954-5.

4 Sulyok E, Varga F, Gyorgy E, Jobst K, Csaba I F. On the mechanism of renal sodium handling in newborn infants. Biol Neonate 1980; 37: 75-9.

Michael F Whitfield Division of Perinatal Medicine, The Hospital for Sick Children, 555 University Avenue, Toronto, Ontario, Canada M5G 1 X8

Dr Dryburgh comments:

It was interesting to learn about the experiences with transpyloric feeding in Sheffield. I agree that the Vygon silicone rubber tube (weighted at the tip with $1 \mathrm{~cm}$ of stainless steel) is not suitable for babies below $750 \mathrm{~g}$ 